\title{
Optimal Design of Concentric Circular Antenna Array Using Particle Swarm Optimization with Constriction Factor Approach
}

\author{
D. Mandal \\ Department of ECE \\ NIT Durgapur-713209
}

\author{
S. P. Ghoshal \\ Department of EE \\ NIT Durgapur-713209
}

\author{
A. K. Bhattacharjee \\ Department of ECE \\ NIT Durgapur-713209
}

\begin{abstract}
In this paper the maximum sidelobe level (SLL) reductions without and with central element feeding in various designs of three-ring concentric circular antenna arrays (CCAA) are examined using Particle Swarm Optimization with Constriction Factor Approach (PSOCFA) to finally determine the global optimal CCAA design. Binary coded Genetic Algorithm (BGA) is also employed for comparative optimization but it proves to be suboptimal. The present paper assumes non-uniform excitations and uniform spacing of excitation elements in each three-ring CCAA design. Among the various CCAA designs, the three-ring CCAA containing central element and 4, 6 and 8 elements in three successive concentric rings proves to be such global optimal design with global minimum SLL $(-17.42 \mathrm{~dB})$ determined by PSOCFA.
\end{abstract}

\section{Categories and Subject Descriptors}

B.8.2 [PERFORMANCE AND RELIABILITY]: Performance Analysis and Design Aids

\section{General Terms}

Algorithms, Design, Theory

\section{Keywords}

Concentric Circular Antenna Array; Non-uniform Excitation; Sidelobe Level; Binary Coded Genetic Algorithm; Particle swarm optimization with constriction factor approach.

\section{INTRODUCTION}

An antenna array consists of multiple stationary antenna elements, which are often fed coherently. There is abundant open technical literatures [1-6], bearing a common target - bridging the gap between desired radiation pattern having nil SLL with what is practically achievable. The primary method in all these research works is improvement of array pattern by manipulating the structural geometry to suppress the SLL while preserving the gain of the main beam.

Among the different types of antenna arrays, CCAA [1,5] have become most popular in mobile and wireless communications. In this paper optimization of CCAA design having uniform interelement separations and non-uniform excitations is performed with the help of a novel evolutionary optimization technique.

In this paper the array factors due to non-uniform excitation in various CCAA design structures are examined to find the best possible design structure using two evolutionary techniques, BGA [4] and PSOCFA [7, 8]. Regarding the comparative effectiveness of the techniques, the newly proposed PSOCFA technique proves to be better in attaining minimum SLL, reduction of major lobe beamwidth and hence minimum "Misfitness" objective function values in the optimization of various CCAA designs.

The rest of the paper is arranged as follows: In section 2, the general design equations for the non-uniformly excited CCAA are stated. Then, in section 3, brief introductions for RGA and PSOCFA are presented. Numerical results are presented in section 4. Finally the paper concludes with a summary of the work in section 5 .

\section{DESIGN EQUATION}

Geometrical configuration is a key factor in the design process of an antenna array. For CCAA, the elements are arranged in such a way that all antenna elements are placed in multiple concentric circular rings, which differ in radii and in number of elements. Fig. 1 shows the general configuration of CCAA with $\mathrm{M}$ concentric circular rings, where the $\mathrm{m}^{\text {th }}(\mathrm{m}=1,2, \ldots, \mathrm{M})$ ring has a radius $r_{m}$ and the corresponding number of elements is $\mathrm{N}_{\mathrm{m}}$. If all the elements in all the rings are assumed to be isotopic sources, then the radiation pattern of this array can be written in terms of its array factor only.

Referring to Fig.1, the array factor, $A F(\phi, I)$ for the CCAA in $x$ $y$ plane is expressed as:

$$
A F(\phi, I)=\sum_{m=1}^{L} \sum_{L=1}^{K_{L}} I_{m} \exp \left[j\left(K r_{m} \sin \theta \cos \left(\phi-\phi_{m}\right)+\alpha_{m}\right)\right]
$$

where $I_{m i}$ denotes current excitation of the $i^{\text {th }}$ element of the $m^{\text {th }}$ ring. $K=2 \pi / \lambda, \lambda$ being the signal wave-length. $\theta$ and $\phi$ symbolize the zenith angle from the positive $z$ axis and the azimuth angle from the positive $x$ axis to the orthogonal projection of the observation point respectively. It may be noted that if the elevation angle is assumed to be 90 degrees i.e. $\theta=90^{\circ}$ then (1) may be written as a periodic function of $\phi$ with a period of $2 \pi$ radian. The angle $\phi_{m i}$ is nothing but element to element angular separation measured from the positive $x$-axis. As the elements in each ring are assumed to be uniformly distributed, we have, 


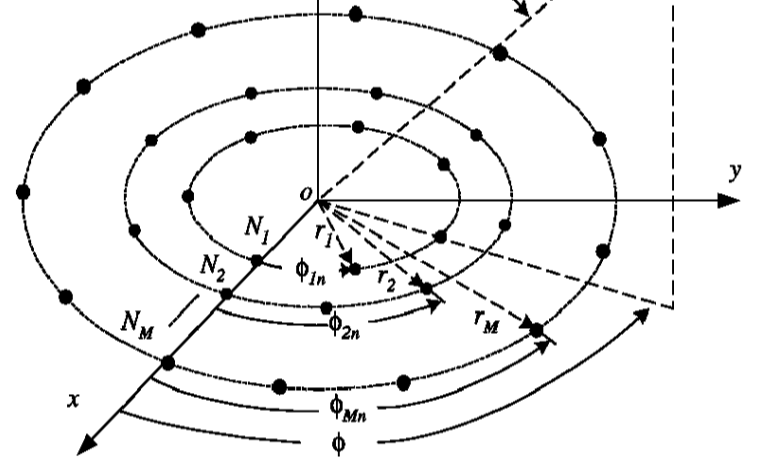

Figure 1. Concentric circular antenna array (CCAA).

$\phi_{m i}=2 \pi\left(\frac{i-1}{N_{m}}\right) ; \quad m=1, \cdots, M ; \quad i=1, \cdots, N_{m}$

$\alpha_{m i}$ is the phase difference between the individual elements in the array, $\alpha_{m i}$ may be written as:

$\alpha_{m}=-K r_{m} \cos \left(\phi_{0}-\phi_{m}\right) ; \quad m=1, \cdots, M ; \quad i=1, \cdots, N_{m}$

where $\phi_{0}$ is the value of $\phi$ where peak of the main lobe is obtained.

After defining the array factor, the next step in the design process is to formulate the objective function which is to be minimized. The objective function "Misfitness" ( $M P$ ') may be written as (4):

$$
\begin{aligned}
M F= & W_{F 1} \times \frac{\left|A F\left(\phi_{m=1}, I_{m v}\right)+A F\left(\phi_{m \sqrt{1}}, I_{m v}\right)\right|}{\left|A F\left(\phi_{0}, I_{m v}\right)\right|} \\
& +W_{F} \times\left(B W F N_{\text {eampand }}-B W F N\left(I_{m}=1\right)\right)
\end{aligned}
$$

$B W F N$ is an abbreviated form of first null beamwidth, or, in simple terms, angular width between the first nulls on either side of the main beam. $M F$ is computed only if $B W F N_{\infty}<B W F N\left(I_{-}=1\right)$ and corresponding solution of current excitation weights is retained in the active population otherwise not retained. $W_{F 1}$ and $W_{F 2}$ are the weighting factors. $\phi_{0}$ is the angle where the highest maximum of central lobe is attained in $\phi \in[-\pi, \pi] . \phi_{m s l 1}$ is the angle where the maximum

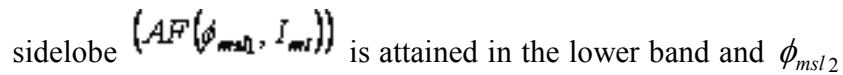
is the angle where the maximum sidelobe $\left(A F\left(\phi_{m \times n}, I_{m}\right)\right)$ is attained in the upper band. $W_{F 1}$ and $W_{F 2}$ are so chosen that optimization of SLL remains more dominant than optimization of $B W F N_{\text {computed }}$ and $M F$ never becomes negative. In (4) the two beamwidths, $B W F N_{\text {computed }}$ and $B W F N\left(I_{-}=1\right)$ basically refer to the computed first null beamwidth in radian for the nonuniform excitation case and for uniform excitation case respectively. Minimization of $M F$ means maximum reductions of SLL both in lower and upper bands and lesser $B W F N$ as compared to $B W F N\left(I_{-}=1\right)$. The evolutionary optimization techniques employed for optimizing the current excitation weights resulting in the minimization of $M F$ and hence reductions in both SLL and $B W F N$ are described in the next section.

\section{EVOLUTIONARY TECHNIQUES EMPLOYED}

\subsection{Binary coded Genetic Algorithm (BGA)}

GA is mainly a probabilistic search technique, based on the principles and concept of natural selection and evolution. At each generation it maintains a population of individuals where each individual is a coded form of a possible solution of the problem at hand and called chromosome. Chromosomes are constructed over some particular alphabet, e.g., the binary alphabet $[0,1]$, so that chromosomes' values are uniquely mapped onto the decision variable domain. Each chromosome is evaluated by a function known as fitness function, which is usually the cost function or the objective function of the corresponding optimization problem.

Steps of BGA as implemented for the optimization of current excitation weights are:

- Initialization of binary chromosome strings of $n_{p}$ population, each consisting of a set of excitations. Size of the set depends on the number of excitation elements in a particular CCAA design

- Decoding of strings and evaluation of "Misfitness" $(M F)^{\prime}$ of each string

- Selection of elite strings in order of increasing $(M F)$

values from the minimum value

- Copying of the elite strings over the non-selected strings

- Crossover and mutation to generate off-springs.

- $\quad$ Genetic cycle updating

- The genetic cycle stops when the maximum number of generations is reached. The grand minimum ( $M F)$ and its corresponding chromosome string or the desired solution are finally obtained.

\subsection{Particle Swarm Optimization (PSO)}

PSO is a flexible, robust population-based stochastic search/optimization technique with implicit parallelism, which can easily handle with non-differential objective functions, unlike traditional optimization methods. PSO is less susceptible to getting trapped on local optima unlike GA, Simulated Annealing etc. Eberhart and Shi [7] developed PSO concept similar to the behavior of a swarm of birds. PSO is developed through simulation of bird flocking in multidimensional space. Bird flocking optimizes a certain objective function. Each agent knows its best value so far (pbest). This information corresponds to 
personal experiences of each agent. Moreover, each agent knows the best value so far in the group (gbest) among pbests. Namely, each agent tries to modify its position using the following information:

- The distance between the current position and pbest.

- The distance between the current position and gbest.

Mathematically, velocities of the particles are modified according to the following equation:

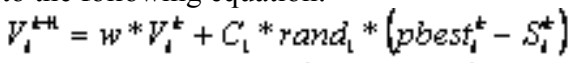

$$
\begin{aligned}
& +C_{2} * \text { rand }_{2} *\left(g b e s t^{*}-S_{1}^{*}\right)
\end{aligned}
$$

where $V_{i}^{k}$ is the velocity of agent $\mathrm{i}$ at iteration $\mathrm{k} ; \mathrm{w}$ is the weighting function; $C_{j}$ is the weighting factor; rand is the random number between 0 and $1 ; S_{i}^{k}$ is the current position of agent $\mathrm{i}$ at iteration $\mathrm{k}$; pbest $t_{i}^{k}$ is the pbest of agent $\mathrm{i}$; gbest ${ }^{k}$ is the gbest of the group. The searching point in the solution space can be modified by the following equation:

$$
S_{i}^{k+1}=S_{i}^{k}+V_{i}^{k+1}
$$

The first term of (5) is the previous velocity of the agent. The second and third terms are used to change the velocity of the agent. Without the second and third terms, the agent will keep on "flying" in the same direction until it hits the boundary. Namely, it corresponds to a kind of inertia and tries to explore new areas. The values of $\mathrm{w}, \mathrm{C}_{1}$ and $\mathrm{C}_{2}$ are given in the next section.

\subsubsection{Particle swarm optimization with constriction} factor approach (PSOCFA):

For PSOCFIWA, the velocity of (5) is manipulated in accordance with (7).

$$
\begin{aligned}
V_{s}^{k+1}= & C F \times\left(V_{s}^{k}+C_{1}^{*} \text { rand } *\left(\text { pbest }-S_{s}^{k}\right)\right. \\
& \left.+C_{3} * \text { rand } d_{3} *\left(g \text { gest }-S_{s}^{k}\right)\right)
\end{aligned}
$$

Normally, $\mathrm{C}_{1}=\mathrm{C}_{2}=1.5-2.05$ and constriction factor $(\mathrm{CF})$ varies from 0.6-0.73. The best values of $\mathrm{C}_{1}, \mathrm{C}_{2}$, and $\mathrm{CF}$ are found to vary with the design sets. The solution updating is same as (6).

\section{EXPERIMENTAL RESULTS}

This section gives the experimental results for various CCAA designs obtained by BGA and PSOCFA techniques. For each optimization technique ten three-ring $(\mathrm{M}=3)$ CCAA structures for two cases as a) without central element feeding and b) with central element feeding in three-ring concentric circular antenna arrays (CCAA) are assumed. Each CCAA maintains a fixed spacing between the elements in each ring (inter-element spacing being $0.55 \lambda, 0.61 \lambda$ and $0.75 \lambda$ for first ring, second ring and third ring respectively). These spacings are the means of the values determined for the ten structures for non-uniform spacing and non-uniform excitations in each ring using 25 trial generalized optimization runs for each structure. This generalized optimization is beyond the scope of this paper. For all sets of experiments, the number of elements of the inner most circle is $\mathrm{N}_{1}$, for outermost circle is $\mathrm{N}_{3}$, whereas the middle circle consist of $\mathrm{N}_{2}$ number of elements. For all the cases, $\phi_{0}=0^{0}$ is considered so that the centre of the main lobe in radiation patterns of CCAA starts from the origin. After experimentation, best proven values of $W_{F 1}$ and $W_{F 2}$ are fixed as 18 and 1 respectively.

The following best proven parameters for the BGA and PSOCFA are i) Initial population $=120$ chromosomes, ii) Maximum number of iteration cycles $=800$ (BGA), 80 (PSOCFA); lesser number of cycles is found to be sufficient for the convergences of PSOCFA, since PSOCFA's convergence rate is higher than BGA's convergence rate, iii) For BGA, Selection probability, Crossover (dual point) ratio and mutation probability $=0.3,0.8$ and 0.004 respectively, iv) For PSOCFA, $\mathrm{C} 1=\mathrm{C} 2=1.5, \mathrm{CF}=$ 0.65 , are the best proven values of the parameters.

Table 1. SLL and BWFN for uniformly excited ( $\left.I_{m i}=1\right)$ CCAA sets

\begin{tabular}{|l|l|l|l|l|l|}
\hline $\begin{array}{c}\text { Set } \\
\text { No. }\end{array}$ & $\begin{array}{c}\text { No. of } \\
\text { elements } \\
\text { in each } \\
\text { rings } \\
\end{array}$ & $\begin{array}{c}\text { Without central } \\
\text { element } \\
\text { (Case (a)) }\end{array}$ & \multicolumn{2}{|c|}{$\begin{array}{c}\text { With } \\
\text { central element } \\
\text { (Case (b)) }\end{array}$} \\
\cline { 3 - 6 } & & $\begin{array}{c}\text { SLL } \\
\text { (dB) }\end{array}$ & $\begin{array}{c}\text { BWF } \\
\text { N } \\
\text { (deg) }\end{array}$ & $\begin{array}{c}\text { SLL } \\
\text { (dB) }\end{array}$ & $\begin{array}{c}\text { BWF } \\
\text { N } \\
\text { (deg) }\end{array}$ \\
\hline I & $2,4,6$ & -6.28 & 128.4 & -8.5 & 140.0 \\
\hline II & $3,5,7$ & -6.89 & 107.2 & -7.5 & 116 \\
\hline III & $4,6,8$ & -5.6 & 90.3 & -6.16 & 95.4 \\
\hline IV & $5,7,9$ & -5.6 & 78.2 & -6.62 & 81.6 \\
\hline V & $6,8,10$ & -5.17 & 68.4 & -6.0 & 71.1 \\
\hline VI & $7,9,11$ & -5.0 & 61.0 & -5.66 & 63.0 \\
\hline VII & $8,10,12$ & -4.78 & 54.8 & -5.38 & 56.4 \\
\hline VIII & $9,11,13$ & -4.64 & 50.0 & -5.17 & 51.3 \\
\hline IX & $10,12,14$ & -4.53 & 46.0 & -5.0 & 47.0 \\
\hline X & $11,13,15$ & -4.45 & 42.0 & -4.88 & 43.2 \\
\hline
\end{tabular}

Each BGA and PSOCFA generates a set of normalized nonuniform current excitation weights for all sets of CCAA. $I_{m i}=1$ corresponds to uniform current excitation. Partial results for BGA and PSOCFA are shown in Tables 2-5. Table 1 depicts SLL values and BWFN values for all corresponding CCAA structures 
Table 2. Current excitation weights, SLL and BWFN for nonuniformly excited CCAA sets (Case (a)) using BGA

\begin{tabular}{|l|cccc|c|c|}
\hline $\begin{array}{c}\text { Set } \\
\text { No. }\end{array}$ & $\begin{array}{c}\text { Current excitation weights } \\
\text { for the array elements } \\
\left(I_{11}, I_{12}, \ldots . ., I_{m i}\right)\end{array}$ & $\begin{array}{c}\text { SLL } \\
(\mathbf{d B})\end{array}$ & $\begin{array}{c}\text { BWF } \\
\mathbf{N} \\
(\mathbf{d e g})\end{array}$ \\
\hline III & 1.0000 & 0.9450 & 0.7463 & 1.0000 & -13.07 & 73.6 \\
& 0.6799 & 0.7126 & 1.0000 & 0.6068 & & \\
& 0.6864 & 1.0000 & 0.6021 & 1.0000 & & \\
& 0.6803 & 0.2289 & 0.6721 & 0.8732 & & \\
& 0.5849 & 0.1872 & & & & \\
\hline V & 0.9219 & 0.7227 & 0.8711 & 0.5781 & -10.81 & 60.4 \\
& 0.5352 & 0.9805 & 0.9922 & 0.2500 & & \\
& 0.8438 & 0.6094 & 0.5898 & 0.2539 & & \\
& 0.5977 & 0.8984 & 0.1523 & 0.8672 & & \\
& 0.8086 & 0.2461 & 0.4844 & 0.4414 & & \\
& 0.5000 & 0.4883 & 0.8750 & 0.5313 & & \\
\hline VII & 0.5898 & 0.5078 & 0.8164 & 0.9492 & -12.0 & 49.5 \\
& 0.7227 & 0.3711 & 0.8086 & 0.9922 & & \\
& 0.6875 & 0.1055 & 0.0742 & 0.6055 & & \\
& 0.4570 & 0.9063 & 0.1836 & 0.2656 & & \\
& 0.6211 & 0.5391 & 0.5938 & 0.4531 & & \\
& 0.8711 & 0.5000 & 0.5469 & 0.5117 & & \\
& 0.2461 & 0.4961 & 0.9570 & 0.429 & & \\
& 0.2422 & 0.4570 & & & & \\
\hline
\end{tabular}

Table 3. Current excitation weights, SLL and BWFN for nonuniformly excited CCAA sets (Case (b)) using BGA

\begin{tabular}{|c|c|c|c|}
\hline $\begin{array}{l}\text { Set } \\
\text { No. }\end{array}$ & $\begin{array}{c}\text { Current excitation weights for } \\
\text { the array elements } \\
\left(I_{11}, I_{12}, \ldots ., I_{m i}\right)\end{array}$ & $\begin{array}{l}\text { SLL } \\
\text { (dB) }\end{array}$ & $\begin{array}{c}\text { BWF } \\
\text { N } \\
(\operatorname{deg})\end{array}$ \\
\hline III & $\begin{array}{llll}0.3789 & 0.7344 & 0.9766 & 0.8164 \\
0.9922 & 0.7148 & 0.5508 & 0.9727 \\
0.7969 & 0.9102 & 0.9805 & 0.6680 \\
0.8750 & 0.6523 & 0.1406 & 0.6406 \\
0.9063 & 0.5508 & 0.1680 & \end{array}$ & -14.53 & 78.3 \\
\hline V & $\begin{array}{llll}0.4961 & 0.7500 & 0.4375 & 0.7422 \\
0.7891 & 0.4219 & 0.4961 & 0.5703 \\
0.1719 & 0.7344 & 0.7461 & 0.5117 \\
0.5000 & 0.4492 & 0.7969 & 0.1992 \\
0.6797 & 0.7109 & 0.4648 & 0.3203 \\
0.3008 & 0.8125 & 0.6055 & 0.3438\end{array}$ & -11.67 & 57.9 \\
\hline VII & $\begin{array}{cccc}0.4570 & 0.5625 & 0.8359 & 0.6328 \\
0.9961 & 0.8633 & 0.7969 & 0.7734 \\
0.9805 & 0.5000 & 0.2500 & 0.1641 \\
0.8398 & 0.2422 & 0.8750 & 0 \\
0.0781 & 0.8750 & 0.4258 & 0.5234 \\
0.1094 & 0.8711 & 0.3828 & 0.2148\end{array}$ & -12.96 & 51.6 \\
\hline
\end{tabular}

\subsection{Analysis of Radiation Pattern of Optimal CCAA}

Figs. 2-3 depict the substantial reductions in SLL with nonuniform optimal current excitations as compared to the case of uniform non-optimal current excitations. All CCAA sets having central element feeding (Case (b)) yield much more reductions in SLL as compared to the same not having central element feeding (Case (a)). As seen from Tables 2-5, SLL reduces to $-13.07 \mathrm{~dB}$ (BGA), - 16.65dB (PSOCFA) for Case (a) and -14.53dB (BGA), $17.42 \mathrm{~dB}$ (grand highest SLL reduction as determined by PSOCFA) for Case (b) with the CCAA set having $\mathrm{N}_{1}=4, \mathrm{~N}_{2}=6$, $\mathrm{N}_{3}=8$. This optimal set along with central element feeding yields grand maximum SLL reductions for both techniques among all the sets. $B W F N$ become narrower for non-uniform optimal current excitation weights as compared to the uniform non-optimal excitations for all sets in both the test cases. For the same optimal CCAA set, the BWFN values are $73.6^{\circ}$ (RGA) and $77.1^{0}$ (PSOCFA) for Case (a), $78.3^{\circ}$ (RGA) and $82.7^{0}$ (PSOCFA) for Case (b) against $90.3^{\circ}$ (Case (a)), 95.4 (Case (b)) for the corresponding uniformly excited CCAA having the same number of elements.

So, these techniques yield maximum reductions of BWFN also for this optimal CCAA (shown as shaded rows in the Tables 2-5). The programming is written in MATLAB 7.5 version on core (TM) 2 duo processor, $3.00 \mathrm{GHz}$ with $2 \mathrm{~GB}$ RAM.

Table 4. Current excitation weights, SLL and BWFN for nonuniformly excited CCAA sets (Case (a)) using PSOCFA

\begin{tabular}{|c|c|c|c|c|c|c|}
\hline $\begin{array}{l}\text { Set } \\
\text { No. }\end{array}$ & \multicolumn{4}{|c|}{$\begin{array}{l}\text { Current excitation weights for the } \\
\text { array elements }\left(I_{11}, I_{12}, \ldots, I_{m i}\right)\end{array}$} & $\begin{array}{l}\text { SLL } \\
\text { (dB) }\end{array}$ & BWF \\
\hline III & $\begin{array}{l}0.0831 \\
0.3860 \\
0.3907 \\
0.4536 \\
0.4867\end{array}$ & $\begin{array}{l}0.6696 \\
0.4254 \\
1.0000 \\
0.2223 \\
0.2533\end{array}$ & $\begin{array}{l}0.0821 \\
0.9383 \\
0.4938 \\
0.4496\end{array}$ & $\begin{array}{l}0.6210 \\
0.3955 \\
0.6647 \\
0.6664\end{array}$ & -16.65 & 77.1 \\
\hline $\mathrm{V}$ & $\begin{array}{l}1.0000 \\
0.5287 \\
0.8663 \\
1.0000 \\
1.0000 \\
0.4853\end{array}$ & $\begin{array}{l}0.6626 \\
1.0000 \\
0.7790 \\
0.8367 \\
0.3719 \\
0.7283\end{array}$ & $\begin{array}{l}0.8101 \\
0.8774 \\
0.6590 \\
0.2976 \\
0.5041 \\
0.3799\end{array}$ & $\begin{array}{c}0.4564 \\
0 \\
0 \\
0.9699 \\
0.4080 \\
0.3983\end{array}$ & -12.55 & 60.6 \\
\hline VII & $\begin{array}{l}0.8709 \\
0.8920 \\
0.6442 \\
0.3796 \\
1.0000 \\
1.0000 \\
0 \\
0.3946\end{array}$ & $\begin{array}{l}0.6058 \\
0.5959 \\
0 \\
1.0000 \\
0.3763 \\
0.1953 \\
0.6097 \\
0.4450\end{array}$ & $\begin{array}{c}0.7297 \\
1.0000 \\
0.1753 \\
0 \\
0.6032 \\
0.5416 \\
1.0000\end{array}$ & $\begin{array}{c}1.0000 \\
1.0000 \\
0.4793 \\
0 \\
0.2461 \\
0.4483 \\
0.5832\end{array}$ & -12.7 & 51.5 \\
\hline
\end{tabular}



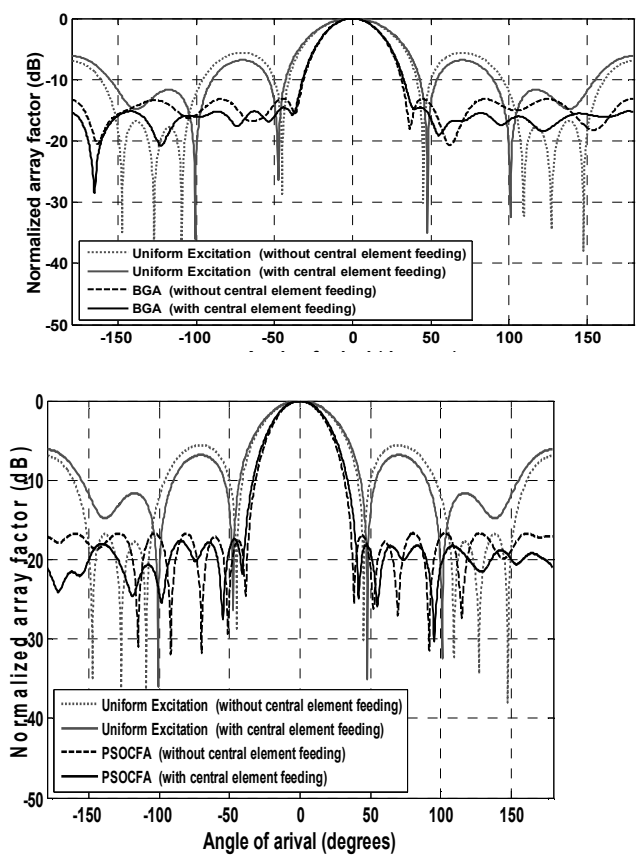

Figure 3. Radiation pattern for a uniformly excited and PSOCFA based non- uniformly excited CCAA $\left(\mathrm{N} \cdot=4 \quad \mathrm{~N}_{\curvearrowleft}=6 \quad \mathrm{~N}_{\curvearrowleft}=8\right.$ elemente $)$

Table 5. Current excitation weights, SLL and BWFN for nonuniformly excited CCAA sets (Case (b)) using PSOCFA

\begin{tabular}{|c|c|c|c|c|c|c|}
\hline $\begin{array}{c}\text { Set } \\
\text { No. }\end{array}$ & \multicolumn{4}{|c|}{$\begin{array}{l}\text { Current excitation weights for } \\
\text { the array elements } \\
\left(I_{11}, I_{12}, \ldots ., I_{m i}\right)\end{array}$} & $\begin{array}{l}\text { SLL } \\
\text { (dB) }\end{array}$ & $\begin{array}{c}\text { BWF } \\
\text { N } \\
\text { (deg) }\end{array}$ \\
\hline III & $\begin{array}{l}0.5382 \\
1.0000 \\
0.8076 \\
0.6295 \\
0.7101\end{array}$ & $\begin{array}{l}0.9293 \\
0.7623 \\
0.7689 \\
0.4938 \\
0.5055\end{array}$ & $\begin{array}{l}1.0000 \\
0.7553 \\
0.6066 \\
0.1398 \\
0.059\end{array}$ & $\begin{array}{l}0.9596 \\
0.5791 \\
0.5161 \\
0.5206\end{array}$ & -17.42 & 82.7 \\
\hline $\mathrm{V}$ & $\begin{array}{l}0.4542 \\
1.0000 \\
0.0549 \\
0 \\
1.0000 \\
0.3535 \\
0.2904\end{array}$ & $\begin{array}{l}0.8413 \\
1.0000 \\
0.9236 \\
1.0000 \\
0.9093 \\
1.0000\end{array}$ & $\begin{array}{l}1.0000 \\
1.0000 \\
0.8775 \\
1.0000 \\
0.4673 \\
1.0000\end{array}$ & $\begin{array}{l}1.0000 \\
1.0000 \\
1.0000 \\
0.4329 \\
0.2894 \\
0.3341\end{array}$ & -13.16 & 60.0 \\
\hline VII & $\begin{array}{l}0.3473 \\
1.0000 \\
1.0000 \\
1.0000 \\
0.0998 \\
0.5670 \\
0.3566 \\
0.1892\end{array}$ & $\begin{array}{c}0.7771 \\
0.7281 \\
1.0000 \\
0.5408 \\
0.4491 \\
1.0000 \\
0.4317 \\
0.6088\end{array}$ & $\begin{array}{l}0.6616 \\
0.7088 \\
0.0241 \\
0.8369 \\
0.5129 \\
0.5432 \\
0.5814\end{array}$ & $\begin{array}{c}0.8692 \\
0.6508 \\
0 \\
0 \\
0.3984 \\
0.3736 \\
1.0000\end{array}$ & -13.68 & 52.8 \\
\hline
\end{tabular}

\section{CONCLUSION}

In this paper, the optimal design of a non-uniformly excited CCAA with uniform inter-element spacing and without / with central element feeding has been described using the evolutionary optimization techniques as BGA and PSOCFA. PSOCFA technique proves to be faster and robust technique; yields optimal excitations and global minimum values of SLL and BWFN for all sets of CCAA designs. BGA is less robust and yield suboptimal results. Experimental results reveal that the design of nonuniformly excited CCAA offers a considerable SLL reduction along with the reduction of BWFN as compared to the corresponding uniformly excited CCAA. The main contribution of the paper is threefold: (i) All CCAA having central element feeding yield much more reduction in SLL as compared to the same not having central element feeding, (ii) The CCAA set having $\mathrm{N}_{1}=4, \mathrm{~N}_{2}=6, \mathrm{~N}_{3}=8$, with central element feeding gives the grand maximum SLL reduction $\quad(\mathbf{- 1 7 . 4 2 d B})$ as compared to all other sets, which one is thus the grand optimal set among all the three-ring structures, and iii) Comparing the performance of both techniques PSOCFA shows the better optimization performance as compared to BGA.

\section{REFERENCES}

[1] Fallahi, R., Roshandel, M. , Effect of mutual coupling and configuration of concentric circular array antenna on the signal-to-interference performance in CDMA systems, Progress In Electromagnetics Research, vol. PIER 76, pp. 427-447, 2007.

[2] Panduro, M. A., Mendez, A. L., Dominguez, R., Romero, G. , Design of non-uniform circular antenna arrays for side lobe reduction using the method of genetic algorithms, Int. J. Electron. Commun. (AEÜ) vol. 60 pp. 713 - 717, 2006.

[3] Shihab, M., Najjar, Y., Dib, N., Khodier, M. , Design of nonuniform circular antenna arrays using particle swarm optimization," Journal of Electrical Engineering, vol. 59(4), pp. 216-220, 2008.

[4] Haupt, R. L., Werner, D. H. , Genetic Algorithms in Electromagnetics, IEEE Press Wiley-Interscience, 2007.

[5] Dessouky, M., Sharshar, H., Albagory, Y., Efficient sidelobe reduction technique for small-sized concentric circular arrays, Progress In Electromagnetics Research, vol. PIER 65, pp. 187-200, 2006.

[6] Yan, K. -K., Lu, Y., Sidelobe Reduction in Array-Pattern Synthesis Using Genetic Algorithm, IEEE Trans. on Antennas and Propagation, vol. 45(7), pp. 1117-1122, July 1997.

[7] Eberhart, R.C., Shi, Y. , Particle swarm optimization: developments, applications and resources, evolutionary computation, Proceedings of the 2001 Congress on Evolutionary Computation, vol. 1, pp. 81-86. 2001.

[8] Mukherjee, V., Ghoshal, S.P. , Comparison of intelligent fuzzy based AGC coordinated PID controlled and PSS controlled AVR system, Int J Electric Power Energy Syst, vol. 29(9), pp. 679-689, 2007. 